\title{
The transposition of the 2014 Directives on public procurement into the Italian law: a challenge for a deep reform of the Italian public procurement system
}

\author{
Valentina Guidi ${ }^{1}$
}

\begin{abstract}
The transposition of the 2014 Directives on public procurement into the Italian law represented a unique opportunity to introduce an ambitious reform of the Italian public procurement system. A strategic document, issued in 2015 by the Italian Government with the support of the European Commission, provided the main objectives, as pointed out in the EU Directives, and the guidelines of the reform which were first transposed by the Italian institutions into the new legislation on public procurement, the Code of public contracts, in 2016 and are currently being implemented by the different actors involved.
\end{abstract}

Simplification has been one of the key issues of the reform process. Simplifying the legislation making the rules clearer and more stable and introducing lighter and flexible regulation. Simplifying and rationalizing the procurement system by reducing the number of contracting authorities through a better demand aggregation and the introduction of a new system to qualify the contracting authorities. Simplifying and shortening the processes and increasing efficiency and transparency through the intensive use of electronic tools. A strategic national e-procurement plan, which is currently being implemented, indicates the necessary steps driving the transition to the full digitalization of procurement by 2020 .

Another key issue of the reform is a more sustainable approach to procurement policies. The transposition law introduces mandatory green criteria to be used by the contracting authorities as technical specification and contract clauses throughout their procurement processes. Moreover, guidance documents have been issued to provide general indications to contracting authorities on how to integrate social considerations throughout their tendering procedure and in the performance of the contract. Italian regions have developed good practices by implementing these guidelines.

The Strategy requires to improve skills and technical knowledge of public buyers for more effective procurement procedures and compliance with public procurement rules. An intensive training plan has been launched in 2017 and has been just completed, providing contracting authorities with a strong and permanent training on public procurement matters .

In order to effectively ensure a correct implementation of the rules and the actions envisaged by the reform a National Coordinator Body has been set up, responsible for monitoring the overall implementation and ensuring a unitary national policy on public procurement.

Even though the transposition of the Directives was timely, a part of the regulation enforcing the Code still has to be adopted. This slowed down the implementation of relevant measures such as the qualification system for contracting authorities. Some of the actions envisaged by the eprocurement plan are still being finalised.

Hopefully all the actors involved will re-launch soon the process in order to achieve all the ambitious objectives of the strategic reform that, in any case, can be seen as a good practice to share.

\footnotetext{
${ }^{1}$ The information and views set out in this article are those of the author and do not reflect the official opinion of the Italian administration and of the Department, nor are binding upon it.
} 


\section{Keywords}

Strategy for the reform of the Italian public procurement system; Code of public contracts; national e-procurement plan; professionalization of public procurement; training plan on public procurement; sustainable procurement; green and social criteria (CAM).

\section{The Strategy for the reform of the Italian public procurement system: a good practice to share}

The transposition of the 2014 Directives on public procurement ${ }^{2}$ into the Italian law has represented a good challenge for introducing a deep reform of the Italian public procurement system.

The need for a reform in the field of public procurement in Italy had been strongly recommended by the European Commission that, in 2014, proposed, among other Member States, also to the Italian authorities an informal partnership in order to elaborate a "Strategy" aiming at deeply reforming the Italian system on public procurement.

This was intended as a new method going beyond the infringement procedures, by using the implementation of the new public procurement Directives as an opportunity to introduce a deep revision not only of the current legislation but also of the general system through an intervention on the structural problems.

To meet this challenge, the Italian government set up a working group, gathering the main national authorities competent for public procurement, which, with the support of the European Commission, drafted the Strategy document.

The first step included a deep analysis of the main critical issues: the complexity of the legislative and institutional framework; the instability of the current regulation (too many and not coordinated rules); the lack of the necessary skills, technical knowledge or procedural understanding for effective public procurement and the need for a stronger professionalization; the complexity of requirements and selection procedures with too many administrative burdens for economic operators, including lack of competition, in particular in concession sector, and lack of efficiency and transparency in the control system; the need for better governance.

In the following step, the working group proposed a number of measures and concrete actions to improve the Italian system. The Strategy focused on the following policy priorities: to set up a structure charged of the coordination of public procurement national policy; to simplify the legislation through the transposition of the Directives and, at the same time, to reduce the current rules (revision of the Code of public contracts); to simplify the procedures by reducing the number of contracting authorities and strengthening e-procurement tools; improving and professionalizing the procurement management; a more efficient monitoring system.

The Strategy was approved by the Italian government in $2015^{3}$ and subsequently endorsed by the European Commission. As an outcome it implemented the main objectives of the EU Directives. Most of the actions proposed by the Strategy were included in the EU Directives transposition legislation act, the ode of public contracts.

\footnotetext{
2 2014/24/EU (the 'Classical Directive'), 2014/23/EU (the 'Concessions Directive'), and 2014/25/EU (the 'Utilities Directive') of the European Parliament and of the Council

${ }^{3}$ Strategy for the reform of public procurement, approved by the Interministerial Committee for european affairs, December 2015.
} 
It is worth mentioning that the adoption of the Strategy and its implementation by 2016 is one of the main measures, intended as "ex ante conditionalities", included in the Action Plan for Public Procurement enclosed to the "Partnership Agreement" signed by Italy and the European Commission on using EU Structural and Investment Funds for growth and jobs in 2014-2020. In 2017 the European Commission assessed that Italy fulfilled all public procurement "ex ante conditionalities".

\section{The main objectives of the EU Directives as implemented by the reform and transposed into the Italian law}

\subsection{A better governance}

The Strategy stressed the lack of a national policy for public procurement and the need for better coordinating the competences spread among different authorities. Following the suggestion of the European Commission, the Code of public contracts states for setting up the National Coordinating Body - NCB (Cabina di regia), responsible for defining a single policy on public procurement in Italy and for cooperating with the European Commission for the correct implementation of public procurement rules. The National Coordinating Body is composed by representatives of the main public entities responsible for implementing public procurement rules both at central and at regional and local level. Representatives of contracting authorities and social and economic operators can be consulted to collect relevant data and information. The NCB started its activity in 2016 and its first task has been to draft the legislative decree which amended the Code of public contracts (see par. 2.2).

\subsection{Simplifying the legislation and rationalising the system}

Italy has been among the first EU countries that have transposed the Directives by the deadline. The legislative decree was adopted in April $2016^{4}$, the new Code of public contracts.

The transposition process has required the full revision of the former Code of public contracts, a single legislative act which contains the provisions applying to both public procurement and concessions both above and below the threshold, both in ordinary and in special sectors. Some of the measures and tools provided by the new directives already existed in the Italian legislation on public procurement. This is the case, e.g., for self-declaration on the fulfilment of requirements for participation to public procurement procedures, for subdivision into lots to facilitate SME's participation (including the obligation of motivation if not), direct payments to subcontractors.

Only one year after it had entered into force, the Code was amended by the legislative decree so called "correttivo", as mentioned above, in April 2017. The "correttivo" did not affect the core of the transposition legislation but introduced some amendments for a correct and more effective implementation of the rules, as requested by the contracting authorities and economic operators.

The main changes introduced by the "correttivo" concern the following issues. Some of the rules applying to above the threshold contracts are extended to below the threshold contracts such as mandatory criteria for green procurement and non-mandatory social criteria (see par. 2.5). Mandatory grounds of exclusion are extended and apply also where the economic operator has been guilty of serious misrepresentation in supplying the information or the documents required. As for the contract award criteria the "correttivo" provides for extending the use of price as the sole award criterion to below the threshold works and services contracts. In applying the most economically advantageous criterion, the weighting to economic elements shall not exceed $30 \%$ whereas qualitative aspects shall be enhanced. Finally, modification of contracts during their term without a new

\footnotetext{
${ }^{4}$ Legislative decree 2016/50 modified by legislative decree 2017/56 ("correttivo")
} 
procurement procedure is allowed also where the modification value does not exceed the EU threshold or is lower than $10 \%$ of the initial value of the contract in case of services and supplies contracts or $15 \%$ of the initial value of the contract in case of works contracts.

One of the main outcomes delivered by the Italian Parliament to the Government was the simplification of the current legislation by reducing the number of rules and avoiding too frequent changes. As a result, it was decided that the primary law, the Code, had to be implemented through guidelines, with more flexible regulation, drown up by the National Anticorruption Authority (ANAC), that is in charge of monitoring and ensuring compliance with the principles of legitimacy and transparency.

Currently eleven guidelines have already been adopted ${ }^{5}$ by ANAC, some binding and others nonbinding. They are addressed to the contracting authorities, in order to fully implement the new public procurement regulatory framework.

In order to simplify and rationalise the system, the Strategy proposed, and the Code introduced the reduction of the number of contracting authorities and a better demand aggregation and centralization of purchases, with the aim of speeding up the awarding procedures, assuring a stronger control on financial flows (spending review), monitoring and preventing corruption; improving the quality of purchasing.

Currently in Italy contracting authorities cannot decide autonomously how to purchase, but are required, depending on their typologies and on contract values, to use the tools provided by Consip - a joint-stock company held by the Italian Ministry of economy and finance and acting as national central purchasing body (MePA, framework agreements, dynamic purchasing system, etc.), or those provided by regional central purchasing bodies, or to use Consip's price and quality benchmarks (where these exist). The tendering procedure remains under the responsibility of the individual contracting authorities only when the use of Consip or other central purchasing bodies tools is not mandatory, but they are always allowed to jointly procure or ask for the support of central purchasing bodies.

The Code also introduced a qualification system to reduce the number of contracting authorities which have to be classified according to their competences and ability in managing the procurement procedures, on the basis of the category and the price of the contract they can perform and registered in a special list managed by ANAC, according to pre-defined criteria such as the control administrative capacity, the skills of the staff, anticorruption measures adopted. The qualified contracting authorities are obliged to standardize and harmonise public procurement procedures. Public contracts above the threshold of $€ 40,000$ ( $€ 150,000$ for public works) can be awarded only by qualified contracting authorities. Contracting authorities, which are not qualified, have to purchase through a central purchasing body or, in alternative, through aggregation with one or more qualified contracting authorities. To implement the qualification system provided by the Code a Government decree still has to be adopted.

\subsection{Strengthening e-procurement tools}

The Strategy highlighted the need for specific governance in e-procurement including a policy to elaborate and implement a plan to enhance the use of electronic tools. The Code of public contracts states that the National Coordinating Body shall promote a national plan for the full digitalization of procurement procedures. For this purpose a working group was set up by the National Coordinator Body in 2017, performing the task of defining and monitoring the roadmap for the

\footnotetext{
${ }^{5}$ https://www.anticorruzione.it/portal/public/classic/AttivitaAutorita/ContrattiPubblici/LineeGuida
} 
eProcurement end to end. The working group is composed by representatives of central and regional authorities and chaired by AgID -Agency for digital Italy, which coordinates the policies for innovation and the actions to foster the adoption of end-to-end electronic public procurement.

The working group has finalized the national strategic plan, which has still to be approved by the National Coordinating Body. As proposed in the Strategy, the National Multi-stakeholder eProcurement Forum was also established, which gathers a variety of relevant stakeholder, with the task of proposing and monitoring the actions to implement the e-procurement in Italy.

The plan defines the actions for the development of the National Public e-Procurement System named ComproPA, which is based on standards and technical specifications in order to support the digital transformation of the procurement processes and the interoperability system at European Level

The actions of the national plan are aligned with the three-year plan for ICT in Public Administration that identifies the investment lines in the ICT sector by the public entities. In order to ensure interoperability of the different systems, which is a pillar of the ICT Strategy, the guidelines on the technical rules for interoperability of eProcurement platforms were issued by AgID in 2016, defining the standards, the technical specifications and the main building blocks which shall be adopted for implementing the national eProcurement system. The Rules refer namely to: CEN TC 434 invoicing, CEN TC 440 electronic Public Procurement, CEF eDelivery building block PEPPOL infrastructures and profiles.

After having identified for each phase of the procurement process the involved actors and systems (e.g. procurement platform, national registers, data providers) security and interoperability requirements for all over the eprocurement process have been defined through specific guidelines which are being finalized by AgID .

The final goal is to achieve the full digitalization of the entire process "procure to pay" (100\%). For this purpose by October 2018, $100 \%$ of purchase and negotiation procedures shall be digitalized. The deadline for the implementation of EU Directives provisions concerning electronic means of communication in public procurement procedures is defined as follows: 17 April 2017 mandatory for central purchasing bodies; 17 October 2018 generally mandatory. By 2019 the electronic post-award phase should be completed and by 2020 the European standard for e-invoicing shall be adopted.

\subsection{Professionalizing the public buyers}

As recommended by the European Commission in its recent initiative on the professionalization of public procurement ${ }^{6}$, public buyers should procure according to the highest standards of professionalism because "enhancing and supporting professionalism among public procurement practitioners can help foster the impact of public procurement in the whole economy".

This aim can be achieved mainly by improving the whole range of professional skills and competences, knowledge and experience of people conducting or participating in tasks related to procurement. Specific actions to enhance public procurement skills were identified in the Strategy and developed by the Italian authorities through an intensive training plan, aimed at providing contracting authorities with a strong and permanent training on public procurement. A structured training system is also included among the criteria required by the Code for qualifying the contracting authorities.

\footnotetext{
${ }^{6}$ Commission Recommendation on 3.10.2017 "Building an architecture for the professionalization of public procurement".
} 
The training programme on public procurement, launched in 2017 and completed half 2018, was partially financed with the EU Structural Funds (2014-2020). It consisted of a basic and a more specific training. The basic module, delivered by the National School of Public Administrations (SNA) through e-learning tools, was directed to staff working in all public authorities involved in public procurement both at central and at regional and local level, providing them with an overall update of the new transposition law (the Code of public contracts and implementation acts). Almost 25.000 people (central, regional and local authorities) were trained. Specialized modules were addressed to staff working in the central purchasing bodies and Regional Managing and Auditing authorities and it was delivered by the SNA with the support of Italian Regions. The content of courses covered the full procurement cycle (from the programming until the performing of the contract) and focused on e-procurement tools and the aggregation procedures such as framework agreements, and 10.000 people were trained.

All the staff trained through the plan received a certification to be used by the contracting authorities to be qualified according to the new system.

New editions of the courses are planned to be launched in 2019. The plan has been included in the collection of good practices from Member States which accompany the European Commission Recommendation.

\subsection{More sustainability: green and social procurement}

The EU Directives provide a toolbox enabling Member States to make more efficient and strategic use of public procurement and the Italian legislation, transposing the Directives, includes, among its main objectives, environmental sustainability and social inclusion .

As for the use of environmental criteria, the Italian legislation goes beyond what the EU Directives require. According to the Code "in the performance of public procurement contracts and concessions, contracting authorities shall comply with environmental, social and labour obligations provided by European and national legislation, collective agreements or international provisions listed in Annex $\mathrm{X}$ (where Annex X refers to the core ILO conventions and environmental conventions)". In order to implement this provision that transposes one of the most relevant provision of the Directives, the Code introduced mandatory rules for contacting authorities. Already before the transposition of the Directives Italy has implemented the National Action Plan (NAP) for green public procurement (GPP), by setting national green criteria ("criteri ambientali minimi"- CAM) for eighteen categories of goods and services, published on the Italian Official Journal. ${ }^{7}$ According to the Code contracting authorities are obliged to introduce in their procurement procedures those green criteria, defined by ministerial decrees, as technical specification and contract clauses. ANAC will monitor on the correct implementation of the CAM and will ensure necessary support and training to the staff of contracting authorities which have to comply with the new obligation.

While Italy has a comprehensive environmental law and experience in using certification as qualification requirements in public contracts, social criteria are less well known. Italy has the world's highest proportion of SA8000 certified manufacturers and, while this can provide useful information about conditions in Italian factories and farms, this cannot be used as a reliable indicator of conditions in supply chains outside of Italy.

Nevertheless, significant progress has been made in the last years. In 2012 a Guide "for the integration of social aspects in public tenders" was published by the Ministry of the Environment, where social criteria refer to criteria for the promotion, throughout the supply chain, of social

\footnotetext{
${ }^{7}$ http://www.minambiente.it/pagina/criteri-vigore
} 
standards relating to human rights and working conditions, internationally recognized and defined by ILO Conventions. The Guide also foresees a "structured dialogue", developed in eight phases, between the contracting authority and the successful tenderer, including follow-up questionnaires, audits and penalties. As an example of good practices, some Italian regions have experienced actions implementing the Guide. The regional purchasing body of Lombardy Region (ARCA Lombardia), acting as a central purchasing body for 1600 contracting authorities (including healthcare structures), has engaged economic operators in a survey on ethical criteria. On the basis of the results of the survey, ARCA Lombardia has integrated the principles of the Guide into eight tenders, four of which are in the healthcare sector for a total purchasing amount of over 990 million euros. Other authorities are following similar approaches, such as Tuscany Region and the Emilia-Romagna regional purchasing bodies (Intercent-ER).

Although only environmental criteria are mandatory in Italy, non-mandatory ethical criteria can be included among the CAM. As an example, the newest ethical criteria have been introduced in the textile sector, one of the highest risk sectors, and include: selection criteria as technical and professional skills of economic operators; the award criteria relating to social characteristics of specific production stages (i.e. the supply chains of the tender object); fair-trade certification; contract clauses.

Among the most relevant developments it is worth mentioning the National Action Plan on Business \& Human Rights 2016-2021 adopted by Italian Authorities on December 2016 (Inter-ministerial Committee for Human Rights -CIDU). The Plan highlights the need to regulate public procurement and business to avoid a skewed market so that economic operators not complying with law or international labour rights conventions should be excluded from public contracts. To achieve these goals, within the overall framework of the implementation of EU directives, the Italian Government is developing the concept of a "human rights clause" to be included as a requirement in all tenders and agreements with enterprises for the purchase of goods and provision of services, with focus on enterprises operating abroad and foreign enterprises.

\section{Final remarks}

Although the transposition of the Directives in Italy was timely, a part of the regulation enforcing the Code still has to be adopted. This slowed down the implementation of relevant measures such as the qualification system for contracting authorities. Some of the actions envisaged by the eprocurement plan are still being finalised.

Hopefully all the actors involved will re-launch soon the process in order to achieve all the ambitious objectives of the strategic reform that, in any case, can be seen as a good practice to share. 